\title{
ASPECTOS DEL SUSTRATO CLÁSICO EN LA POESÍA DE MELÉNDEZ VALDÉS ${ }^{1}$
}

\author{
Antonio Ramajo Caño \\ Universidad de Salamanca.
}

1. Mucho es lo que beneméritos estudiosos han aportado al conocimiento de la poesía de Meléndez Valdés. Con todo, aún quedan esfuerzos por hacer para dilucidar puntos concretos del sustrato clásico que, en buena medida, vertebra la obra de nuestró poeta. He aquí, en efecto, que nos encontramos con un autor impregnado de abundantes lecturas y buen conocedor de los clásicos, por lo que se hace imprescindible el laborar en el análisis de sus modelos. Testimonios explícitos conservamos de la actividad lectora del poeta. La correspondencia con Jovellanos nos informa cumplidamente de las lecturas del joven Batilo $^{2}$. Entre los autores clásicos favoritos figura en principal lugar Horacio ${ }^{3}$, a cuyo estudio se dedica incluso en los períodos de vacación ${ }^{4}$. En sustitución del Maestro Alba explicará al poeta latino, en la cátedra de Humanidades de la Universidad de Salamanca, a partir de $1778^{5}$. Y cuando oposita a esta misma Cátedra el 19 de enero de 1781, traduce la oda $\mathrm{X}$ del libro II del venusino ${ }^{6}$. Por otra lado, el pro-

' El presente trabajo tiene como lejana base una reseña propia, de la antología de Meléndez Valdés editada por Palacios (1979); tal reseña se publicó anónima, por descuido, en Studia Philologica Salmanticensia, 4 (1979), pp. 285-294. De la autoría de aquel juvenil trabajo da fe el certificado manuscrito, que conservamos, del entonces director de la revista, el llorado don Eugenio de Bustos Tovar. Las páginas que al lector presentamos se apartan grandemente de aquel primer escrito: se han estudiado otros versos de Meléndez; se ha intentado poner al día la bibliografía.

${ }^{2}$ Demerson (1961: 53-56) ha establecido la lista de lecturas del poeta.

${ }^{3}$ Para el gusto horaciano dieciochesco, cf. Durán (1999).

${ }^{4}$ En carta a Jovellanos (Segovia, 11 de julio de 1778) dice Meléndez que le acompañan, además de algunos libros de Derecho, «el Tasso, las Noches de Young, y Horacio y Homero, y las Cartas de Plinio» (en Cueto 1893: III, p. 48).

${ }_{5}^{5}$ Cf. carta a Jovellanos fechada en Salamanca, 3 de noviembre de 1778 (en Cueto 1893: III, p. 81). El Maestro Alba explicaba prosodia, métrica y mitología grecolatinas, basándose principalmente en los textos de Homero y Horacio. A sus clases había asistido Meléndez en el curso de 1774-1775 (Alarcos 1926: 145). Para la faceta profesoral de Meléndez, cf. Astorgano (2001).

${ }^{6}$ Cf. Alarcos (1926: 151-155). La traducción puede leerse en Poesías inéditas, n. ${ }^{\circ}$ 39, pp. 216-217, y en Obras en verso, II, p. 749. Meléndez tradujo, además, otras composi-

Rlit, LXIV, 127 (2002), 41-61 
pio Meléndez cuenta cómo Horacio ha sido siempre poeta suyo predilecto: «...han sido mis guías el mismo Horacio, Ovidio, Tibulo, Propercio y el delicado Anacreonte» ${ }^{7}$. Con este último no se refiere Meléndez al poeta del siglo VI a. C., sino a la colección de Anacreónticas, editadas por primera vez en París, en $1554^{8}$.

Por otro lado, el amor horaciano debió de acrecentarse con la compañía de amigos que compartían un similar gusto, como Fray Diego González ${ }^{9}$, Jovellanos ${ }^{10}$, Cadalso y José Iglesias de la Casa ${ }^{11}$.

Y tal pasión literaria no decreció con el paso del tiempo. Muchos años después, cuando en 1815, en Nimes, Meléndez expresa en el prólogo a sus versos que el lector podrá encontrar en ellos el amor «a la tranquilidad, a la medianía» ${ }^{12}$, no hace sino mostrar el deseo de que su obra esté empapada de espíritu horaciano, de aquella gozosa aurea mediocritas expresada en multitud de composiciones y, en particular, en la oda décima del libro segundo de Horacio ${ }^{13}$.

2. La lira del poeta extremeño tañerá melodías diferentes. Con todo, Meléndez rehúye en su primera época, deliberadamente, los tonos graves, para refugiarse en lo intranscendente y gozoso: «No con mi blanda lira/ serán en ayes tristes/ lloradas las fortunas/ de reyes infelices;/ ni el grito del soldado,/ feroz en crudas lides (...)./ Muchado soy, y quiero decir más apacibles/ querellas, y gozarme/ con danzas y convites» ${ }^{14}$. No nos interesa rastrear la trayectoria vital del poeta configurada en sus versos. Intentamos simplemente encontrar la huella de la tradición clásica, que anotamos con austeridad, sin apenas comentario, como labor que nos parece urgente.

ciones horacianas (Demerson 1958): véase el texto en Obras en verso, II, pp. 738-758. Cf. Polt (1995) para algunas observaciones sobre Meléndez como traductor.

7 Véase la «Advertencia» al frente de Poesías (1797), t. I, p. XI.

${ }^{8}$ Este seudo Anacreonte plantea grandes problemas de cronología: cf. Brioso Sánchez (1981: XXVII-XLVI). Meléndez debió de leer tales poemas directamente en griego, aunque tuviera también la mediación de Villegas. Cf. Colford (1942: 143). Cf. las precisiones de Polt (1995); vid., además, Pabón (1975). Meléndez había estudiado griego, asistiendo a las clases del catedrático de la Universidad de Salamanca P. Zamora (Alarcos García 1926: 144-145; Gil 1974). Para la obra de este helenista, cf. Ramajo (1978).

${ }_{9}$ El biógrafo del agustino, Fray Juan Fernández, dice de él que conocía a Horacio y a Fray Luis de tal manera que podría recitar las odas de uno y otro de memoria (Cueto 1952: I, p. 117).

10 Para el influjo de Horacio en Jovellanos, cf. Fernández Vallina (1994).

1 Del horacianismo de estos dos últimos poetas citados alguna referencia se dará en el presente trabajo.

${ }_{12}$ Cf. Poesías (1820), t. I, p. XIII.

13 Para los diversos tópicos y modalidades literarias de base horaciana conviene tener presente el trabajo de Alvar (1994).

${ }_{14}$ «A mis lectores», vv. 1-16, Obras en verso, I, p. 73. Colford (1942: 145) señala solamente la influencia de Anacreonte en este texto. 
Por ello, reparando en los versos citados, conviene precisar que Meléndez utiliza aquí el conocido procedimiento de la recusatio, algo que, por otro lado, encaja bien, al situarse el poema como especie de prólogo ${ }^{15}$, pues tal recurso retórico consiste en deslindar campos semánticos que el poeta tocará con su pluma. Normalmente, el autor afirmará su preferencia por los temas líricos frente a los serios, propios de la épica o de la tragedia.

La recusatio aparecerá en otros lugares de la obra de Batilo. He aquí cómo se combina con la priamel ${ }^{16}$, consistente en resaltar los propios gustos frente a los de otras personas (con marcas sintácticas, del tipo, en latín, alii-ego), en la oda anacreóntica LIX, en que Baco y Cupido han pedido al poeta que se dedique a la lírica: «Deja que otros se encumbren/ allá sobre el Olimpo/ y hasta del sacro Jove/ indaguen los designios,/ que la brillante gloria/ los lleve embebecidos/ tras el sublime lauro,/ sin miedo a sus peligros./ Tú apocado y humilde/ prefiere en tus destinos/ a las palmas guerreras/ el pacífico olivo» (vv. 45-46) ${ }^{17}$. De nuevo se encuentra el mismo recurso en la oda I de «La paloma de Filis»: «Otros cantan de Marte/ las lides y zozobras/ o del alegre Baco/ los festines y copas (...)/ Pero yo sólo canto/ con cítara sonora/ de mi querida Filis/ la nevada paloma» (vv. 1-12) ${ }^{18}$. En este poema se refleja, por otro lado, la faceta catuliana de canto a los pájaros de la amada, intermediarios entre los dos miembros de la pareja ${ }^{19}$.

${ }^{15}$ Cf., para la recusatio, Ramajo (1998) y Montes Cala (1999). En efecto, este poema figura como especie de prólogo en todas las ediciones en las que intervino el autor que nosotros hemos podido consultar: cf. Poesías (1797), t. I, p. 1; Poesías escogidas (1811), t. I, pp. 1-2; y Poesías (1820), t. I, p. 2.

${ }^{16}$ Cf. Race (1982) y Ramajo (1994).

${ }^{17}$ Cf. Obras en verso, I, p. 142. El propósito de limitarse a temas amorosos surge por doquier: «Pero Amor sonriose,/ armó el arco y me dijo:/ 'Para que mejor cantes,/ toma esta flecha, amigo'» (oda anacreóntica LXXVII, vv. 13-16: Obras en verso, I, p. 151). Y otra recusatio brota en la oda anacreóntica LXVI: «Iba a cantar de Marte/ las guerras y las iras...» (vv. 1-2: Obras en verso, I, p. 146: los editores remiten a la monóstrofe 2 del Anacreonte de Villegas). La recusatio y la priamel aparecen en la epístola II, dedicatoria de las poesías de 1785 a Jovellanos: otros —viene a decircantarán las hazañas militares: «Mi pacífica musa no ambiciosa/ se atreve a tanto; el delicado trino/ de un colorín, el discurrir süave/ de un arroyuelo entre pintadas flores (...)/ y una mirada de Dorila o Filis» (vv. 46-51: Poetas líricos del siglo XVIII, t. II, pp. 764-765).

Por otro lado, el que personajes mitológicos o seres abstractos como Amor se aparezcan al poeta para pedirle que confine sus versos en el campo lírico, lejos de la épica, es recurso aprendido de Ovidio, quien, a su vez, imita a Calímaco: véanse los textos oportunos en Ramajo (1998: 1285-1286).

18 Cf. Obras en verso, I, p. 167.

19 Véase Endecha I, vv. 1-2, Obras en verso, I, p. 278: «Lloren los pajarillos,/ lloren la triste suerte....» (ha muerto el pajarillo de Filis). Cf. Catulo, 3: «Lugete, o Veneres Cupidinesque...» ('Llorad, Venus y Amores...': influjo señalado por los editores). De este poema catuliano compuso una traducción Cadalso: «De mi querida Lesbia/ ha muerto el pajarito...» (Poetas líricos del siglo XVIII, t. I, p. 269). 
$Y$ no es suficiente, en nuestra opinión, para establecer tal prefencia semántica, hablar del temperamento sensual de Batilo, de las corrientes literarias del momento propensas a esta voluptuosidad, ni siquiera de la más que probable influencia de Cadalso ${ }^{20}$. Todos estos factores son ciertos; pero es preciso tener en cuenta, además, el empuje de Horacio: «Nos convivia, nos proelia virginum/ sectis in iuvenes ungibus acrium/ cantamus, vacui sive quid urimur/ non praeter solitum leves» (I, vi, 17-20: 'Nosotros los banquetes, nosotros los combates de doncellas guerreras, de uñas cortadas, contra mozos, cantamos, tanto si nuestro corazón está libre como si está abrasado por algún fuego, como es frecuente') ${ }^{21}$.

En un determinado momento, parece que Valdés se muestra más radical y quiere abandonar la poesía lírica, como si cultivara el tópico que consideraba tal mester como delicta iuventutis. Y escribe el poema titulado «A Anfriso. Que ni la voz ni la lira son ya, por mis años, a propósito para la poesía» (oda anacreóntica $\mathrm{LV}^{22}$ ). Interesa en los versos que reproducimos la aparición de la citada priamel: «Tú en tanto a quien los años/ y el claro dios del Pindo/ adulan y en sus redes/ prendió el alado Niño,/ feliz mis huellas sigue/ (...) Yo en tus aplausos loco,/ mientras que al negro olvido/ me robas tú en tus versos,/ del mismo Apolo dignos,/ diré gozoso a todos (....)» (vv. 125-141) ${ }^{23}$. Acaso haya también un tono luisiano, de la oda XI, «A Juan de Grial», en la contraposición entre quien puede escribir y aquél falto ya de fuerzas, aunque en Meléndez falte todo el tono trágico del agustino.

Incluso, muy pronto (1774), Meléndez había escrito un «Soneto renunciando a la poesía después de la muerte de Filis» ${ }^{24}$. La factura es clásica,

${ }^{20}$ Véase, para la recusatio, aquel poema de Cadalso que comienza: «No tocaré materias superiores/ (...) Ya canto de pastoras y pastores/ las fiestas, el trabajo y los amores» (Poetas líricos del siglo XVIII, I, pp. 248-249). Cf. también, para la recusatio en Cadalso, los poemas titulados: «Declara el autor su amor a Filis» y «Fruto que deseo sacar de mis poesías» (ibíd., pp. 249-250). Para Cadalso como adalid del grupo salmantino, cf. todavía Real de la Riva (1948: 346-352 y 362); para el valor de la amistad en Cadalso, cf. Gies (1985).

También Iglesias de la Casa, poeta de fuerte huella clásica, se sirve de la recusatio: cf. égloga II: «Préstame, musa, espíritu canoro;/ diré con tu favor, no aquellas lides/ de Marte insano, que fulmina horrores,/ sino tiernas endechas de pastores» (vv. 5-8, Poetas líricos del siglo XVIII, t. I, p. 450).

${ }^{21}$ El eco de Horacio se percibe en los siguientes versos de Villegas, poeta querido de Meléndez: «que yo de los guerreros/ no trato las peleas,/ sino las de las niñas,/ porque éstas son mis guerras» (Cantilena XXXV, «De sí mismo», vv. 21-24, Eróticas o amatorias, p. 159). 1808.

${ }^{22}$ La oda está fechada por Polt y Demerson (1981-1983: I, p. 135-137) entre 1798-

${ }^{23}$ Cf. Obras en verso, I, p. 136-137.

${ }^{24}$ El soneto aparece insertado, significativamente, tras un «Epitafio del sepulcro de Filis», en diversas ediciones: 1797: t. II, pp. 83-84; 1811: t. II, p. 92; 1820: t. II, p. 288. Tal orden se respeta en Obras en verso, I, p. 496. 
por cuanto el poeta cuelga en un árbol el instrumento que le había servido para cantar a la musa, como hacían los romanos que dedicaban votivamente la herramienta esencial de su oficio cuando les llegaba la retirada: «Quédate, adiós, pendiente de este pino/ sin defensa del tiempo a los rigores,/ cítara en que canté de mis amores...» Meléndez sigue una tradición horaciana (Carm., I, v), que en seguida veremos, matizada, por ejemplo, por Sannazaro, Arcadia (en una especie de epílogo en que se despide de la zampoña) y Lope de Vega ${ }^{25}$.

A veces, el poeta más que jubilar su lira lo que pretende es liberarse de los amores. Se introduce en la llamada renuntiatio amoris: «Quédense de tu templo ya colgados/ vistiendo sus paredes mis despojos/ ya basta Amor de engaños y de enojos/ no quiero más tu guerra y tus cuidados» («Sonetos», XXIII, vv. 1-4) ${ }^{26}$. Meléndez parece recordar unos versos de Carmina, I, v, 13-16, en que el poeta, como un náufrago superviviente, confiesa haberse salvado del mar de amores: «Me tabula sacer/ votiva paries indicat uvida/ suspendisse potenti/ vestimenta maris deo» ('El sagrado muro muestra, con su tabla votiva, que yo he consagrado al poderoso dios del mar mis húmedos vestidos'). Tenemos aquí a la par el tópico del navigium amoris $^{27}$. En Meléndez, con todo, a diferencia de lo que acontece en el poema horaciano, triunfa finalmente el amor.

3. Muchos son los versos que Valdés dedicó a la musa jovial, en la que, a veces, se entrevera, una nota de melancolía. La preocupación de nuestro poeta por el paso del tiempo y el deseo de gozar de la brevedad de la existencia son lugares comunes que abundan en la obra horaciana. Contentémonos aquí con señalar sólo algunos préstamos tomados por Meléndez, tarea, sin duda, difícil por cuanto, si es visible la huella del latino, resulta arduo y arriesgado precisar el lugar exacto que ha inspirado a nuestro poeta. Por otro lado, con frecuencia se interfieren distintos textos de Horacio, que, luego, en Meléndez constituyen una unidad: es el

\footnotetext{
${ }^{25}$ Cf. Ramajo (1998: 1292).

${ }^{26}$ Cf. Obras en verso, I, p. 468. También aparece la renuntiatio en el soneto que

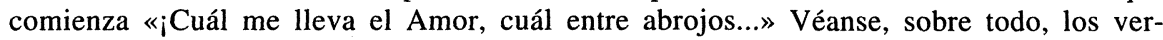
sos: «Muévate a compasión el dolorido/ cuerpo, tirano Amor, muévate el ruego/ de un infeliz y alíviame el tormento» (v. 9-11), en los que hay eco de otro lugar horaciano: «Intermissa, Venus, diu/ rursus bella moves? Parce, precor, precor (...)./ Desine, dulcium/ mater saeva Cupidinum...» (IV, i, 1-5: ‘ ¿De nuevo, Venus, las guerras tanto tiempo apagadas enciendes? Ten piedad, por favor, por favor, madre cruel de dulces Deseos').

${ }_{27}$ Tópico, por otro lado, encontrable también en la poesía elegíaca latina (Alvar 1994: 137). Los poetas del Siglo de Oro español lo reelaboraron una y otra vez. Baste citar a Garcilaso: «Tu templo y sus paredes he vestido/ de mis mojadas ropas y adornado,/ como acontece a quien ha ya escapado/ libre de la tormenta en que se vido" (soneto VII, vv. 5-8); y a Cristóbal de Mesa: «Ofrezco a tu deidad, sacro Neptuno,/ el húmido vestido, que devoto/ saqué del mar furioso (...)» (vv. 1-3, Rimas, ed. de 1618, fol. 113v. ${ }^{\circ}$ ).
} 
conocido fenómeno de la contaminatio. Así, en los siguientes versos: «Que las horas escapan/ fugaces y callando/ y en pos nos precipita/ del tiempo el rudo brazo./ Ved, si no, cuál las rosas/ dan su vez al verano,/ y al enero aterido/ el otoño templado» («De un convite», vv. 85-92) ${ }^{28}$.Parece que el poeta recuerda sus lecturas de dos odas horacianas diferentes. En primer lugar, la catorce del libro segundo: «Eheu fugaces, Postume, Postume,/ labuntur anni nec pietas moram/ rugis et instanti senectae/ adferet indomitaeque morti» (vv. 1-4: ‘¡Ay, Póstumo, Póstumo!, los años se deslizan fugitivos, y la piedad no puede retrasar las arrugas, la vejez amenazadora y la muerte invencible'). En segundo lugar IV, vii: «Frigora mitescunt Zephyris, ver proterit aestas,/ interitura simul/ pomifer autumnus fruges effuderit, et mox/ bruma recurrit iners» (vv. 9-12: 'Los fríos se suavizan con los céfiros, el verano aniquila a la primavera, que perecerá en cuanto otoño, portador de cosechas, derrame sus frutos; y al instante retorna el invierno sin vida').

En el mismo poema, en otros versos, resulta fácil establecer la fuente: «Del día que nos ríe/ gocemos, pues en vano/ será inquirir si un otro/ nos lucirá más claro» («De un convite», vv. 101-104 ${ }^{29}$ ). He aquí una versión del famosísimo verso «carpe diem, quam minimum credula postero» (I, xi, 28: 'goza del hoy, nada confiada en el mañana'). Son evidentes la concisión y gravedad de Horacio frente al circunloquio y la ligereza de Meléndez, debidos, acaso, al personal intento de crear una atmófera exenta del dramatismo que colorea la composición del latino.

Tanto Menéndez Pelayo ${ }^{30}$ como Colford ${ }^{31}$ han hablado del tono horaciano de la oda «Que es locura engolfarse en proyectos y empresas desmedidas, siendo la vida tan breve y tan incierta». Pero ninguno de los dos ha precisado más. Y es comprensible, porque este tema parece en muchas composiciones de Horacio: en las Odas, I, iv, vii y ix; II, x, xi y xvi; III, xxix; IV, vii. También en el epodo segundo (Beatus ille). Y no se pretende ninguna exhaustividad en la pasada relación.

Con todo, se puede precisar más. Conviene señalar aquellos versos de Meléndez que ofrecen una relación bastante clara con pasajes de Horacio. Y así nos permitimos presentar unos versos de Carm., III, xxix, al lado de

${ }^{28}$ Cf. Obras en verso, I, p. 92: los editores dicen, p. 91, que « a partir del v. 85 recuerda [esta oda] la XI del libro I de Horacio».

${ }^{29}$ Cf. Obras en verso, I, p. 92. Cf., para el carpe diem, González de Escandón (1938). Otros tópicos utiliza Meléndez relacionables con la antigüedad clásica. Así, se sirve de la tristeza del ruiseñor para expresar sus propios lamentables sentimientos: « $i \mathrm{Oh}$ ruiseñor cuitado!/ Tu delicado acento,/ tus trinos melodiosos,/ tu revolar inquieto/ me dicen los dolores/ de tu sensible afecto./ ¡Felice tú, que sabes/ tan dulce encarecerlo!» («Odas anacreónticas», XLIII, «De la noche», Obras en verso, I, p. 122). Al estudio del topos ha dedicado espléndidas páginas M. ${ }^{a}$ Rosa Lida (1939).

${ }^{30}$ Cf. Horacio en España, t. II, p. 138.

${ }^{31}$ Cf. Colford (1942: 186). 
otros de Valdés: «Prudens futuri temporis exitum/ caliginosa nocte premit deus/ ridetque, si mortalis ultra/ fas trepidat. Quod adest memento/ componere aequus...» (vv. 29-33: 'La divinidad, prudente, esconde la salida del tiempo futuro en noche cubierta de niebla, y se ríe si el hombre mortal se afana tembloroso fuera del límite establecido. Acuérdate de ordenar, juicioso, el presente'); «Mejor sería que imites/ esta feliz prudencia; en lo presente/ la esperanza limites (...). Un velo denso, oscuro,/ que en vista humana traspasar no cabe,/ envuelve lo futuro;/ el cielo en triple llave/ lo guarda,/ que abrir solo el tiempo sabe» (vv. 71-8032). En esta ocasión sí ha conseguido Meléndez imitar la gravedad del original.

La influencia de Horacio se manifiesta incluso en la composición que lleva por título «De las navidades». Es evidente que Meléndez imita a Villegas ${ }^{33}$; pero hay una inquietud por el paso del tiempo ausente en el poeta áureo. Quizá tal desazón proviene de Horacio. Desde luego, los versos que a continuación presentamos nós recuerdan aquellos de IV, vii, citado anteriormente: «Yo vi el abril florido/ que el valle alegre borda,/ y al abrasado julio/ vi marchitar su alfombra./ Vino el opimo octubre,/ las uvas se sazonan,/ mas el diciembre helado/ le arrebató su pompa» («Odas anacreónticas», XXX, vv. 25-32 ${ }^{34}$ ).

El tono hedonista, en el que no falta la nota grave, según se ha señalado, brota una y otra vez en Meléndez bajo la inspiración del venusino. Así, se observa en el siguiente poema recogido por Rodríguez Moñino, en el que, además, parece notarse un cierto eco gongorino: «Ya, ya con sus rigores/ está en casa el Invierno:/ pues, ¡ea, mi Belisa,/ lleguémonos a el [sic] fuego,/ asemos las castañas...,/ bebamos de lo añejo/ que nos eche escarchas/ el insolente Enero!» («Odas anacreónticas», LXVIII) ${ }^{35}$. Ese $Y a$, $y a$, inicial es claramente horaciano, como se verá posteriormente. Por otro lado, viene al recuerdo la oda $\mathrm{I}$, ix, la que comienza «Vides ut alta stet nive candidum», en la que en un día de invierno, de intenso frío, el poeta recomienda a Taliarco el olvido de todos los cuidados, junto al fuego, con el dulzor de un vino de cuatro años («quadrimum merum») ${ }^{36}$. Ese mismo poema de Horacio debió de influir en el titulado «De la nieve» (oda anacreóntica, XLVII): «Dame, Dorila, el vaso/ lleno de dulce vino,/ que sólo en ver la nieve/ temblando estoy de frío» (vv. 1-4) ${ }^{37}$.

\footnotetext{
${ }^{32}$ Cf. Obras en verso, II, p. 681.

${ }^{33}$ En la cantilena titulada «De la navidad» (Palacios 1979: 163, nota 7).

${ }^{34}$ Cf. Obras en verso, I, p. 107.

${ }^{35}$ Cf. Poesías inéditas, I, p. 147. En Obras en verso, t. I, p. 147, en lugar de Belisa, se edita Dorila.

${ }^{36}$ Tal oda horaciana influye, a decir de D. Alonso (1967: II, 81), en la letrilla gongorina «Ándeme yo caliente/ y ríase la gente», letrilla que parece influir en Meléndez.

${ }^{37}$ Cf. Obras en verso, I, p. 126. También influye probablemente en la oda XIV; «A mi amigo don Manuel Lorieri en sus días»: «Desdeña, Anfriso, del enero triste/ las ru-
} 
Existe un texto de Meléndez bien necesitado de comentario. He aquí sus versos: «Y el amor en su vaso/ nos diera el quinto néctar delicioso/ en el lance glorioso/ do jamás anda escaso/ en derramar su cebo/ y es paso un gusto de otro gusto nuevo» («Los besos de amor», XII, vv. 19-24 ${ }^{38}$ ).

Es obligado dar una explicación del quinto néctar delicioso. Nos arriesgaremos a citar dos versos de Horacio: «...oscula, quae Venus/ quinta parte sui nectaris imbuit» (I, xiii, 15-16). Así los tradujo Villegas: «...los besos que ha colmado/ Venus de aquella partel quinta que de su néctar les reparte» ${ }^{39}$.

Los besos son la quinta parte del néctar. Es decir, son dos veces más dulces que la miel, pues ésta, según la tradición alejandrina, era considerada como la novena o décima parte del néctar ${ }^{40}$. Aquí se encuentra, a nuestro juicio, la clave para la comprensión del texto. Meléndez, sin duda, leyó el pasaje horaciano. Contaba, además, con una tradición donde, tópicamente, se equiparaba el beso con el néctar. Contentémonos con citar unos versos de Góngora: «La dulce boca que a gustar convida/ un humor entre perlas destilado,/ y a no invidiar aquel licor sagrado/ que a Júpiter ministra el garzón de Ida» ${ }^{41}$.

La influencia horaciana desciende, a veces, al detalle. Así, en la oda XVII, «Himno a Venus» ${ }^{42}$, el poema comienza con un «Desciende del Olimpo, alma Citeres...», que recuerda el «Descende caelo et dic age tibia,/ (...) Calliope» (III, iv, 1-2), aunque, luego, cada poeta siga un curso diferente. Incluso el adjetivo alma, 'nutricia', es de claro sabor clásico, usadísimo por Virgilio y por Horacio ${ }^{43}$. Pero la oda citada guarda ciertas complicaciones. Como subtítulo pone traducido. ¿Cuál es el modelo? Ade-

das furias y aterido ceño,/ su cana faz, su nebulosa vista/ plácido mira» (vv. 1-5: Obras en verso, t. II, p. 645). A continuación viene la invitación al vino y la alegría.

${ }^{38}$ Cf. Obras en verso, I, pp. 300-301.

${ }^{39}$ Eróticas o amatorias, p. 82.

${ }^{40}$ Para este complicado pasaje horaciano, cf. Villeneuve (1929: 24, nota 2).

${ }^{41}$ Sonetos completos, ${ }^{\circ}{ }^{7} 70$, vv. $1-4$, p. 135 . Se trata de un tópico que encontramos en otros lugares de la obra de Meléndez: «Con su boca de perlas,/ ¡qué palabras me dijo, ay, gloria mía!/ Yo acudí por cogerlas/ y del néctar bebí que ella vertía» (vv. 1720, Poesías inéditas, pp. 221-222); «Y no son más dulces/ las mieles de Hiblía/ que el néctar que en ellos [los besos]/ tus labios destilan» («Los besos de amor», 20, vv. 9-12, Obras en verso, I, p. 308); «Mas los labios floridos/ asaltad, susurrantes/ de mi amada, y el néctarl que destilan robadle,/ (...) que es su boca divina/ venero inagotable/ de miel suave y pura,/ de gracias celestiales» («Odas anacreónticas», XXXI, «A las abejas», vv. 17-31, Obras en verso, I, p. 109). La sinonimia néctar-miel remonta, al menos, a Virgilio, Geórgicas, IV, 164 (aunque en el poeta latino no se emplea con sentido amatorio).

${ }_{42}$ Cf. Obras en verso, II, pp. 649-650.

${ }^{43}$ Cf. también la oda anacreóntica LVII, «De mi suerte», v. 21: «...almos avisos» (Obras en verso, I, p. 139). Fray Luis gustó del adjetivo: «Alma región luciente» (XIII, 1). En la edición, en prensa (Crítica), de las Poesías del agustino, al comentar el citado verso, reunimos pasajes clásicos en que aparece el adjetivo. Cf. ya Alcina (1989: 142). 
más del texto horaciano señalado, cabe tener presente otro lugar del mismo poeta, Carmina, I, xxx: «O Venus, regina Cnidi Paphique», de cuyo verso primero se hace eco explícito Meléndez en «Ven, joh de Gnido y Pafos protectora!» (v. 13). Nuestro poeta, en verdad, da una versión muy ampliada y libre de esta última oda latina. La idea de ambas composiciones, modelo y copia, consiste en una petición para que Venus se presente y todo lo llene de alegría y amor. El autor extremeño se ha servido, pues, de la contaminatio de dos textos del poeta venusino.

Pongamos otro ejemplo de detalle que remite a Horacio, detalle del cual ya antes hemos dado referencia. La oda novena, dentro del grupo de las Anacreónticas ${ }^{44}$, comienza con un «Ya torna mayo alegre...» (v. 2), en que el adverbio de tiempo remite directo a Horacio: IV, vii: «Diffugere nives, redeunt iam gramina campis...» ('Las nieves huyeron y ya retornan las hierbas a los campos'); o IV, xii: «Iam veris comites, quae mare temperant...» ('Ya los compañeros de la primavera, que apaciguan el mar...'). Idéntico inicio se encuentra en otro poema de Meléndez: « $Y a$ la primavera/ tranquila y riente/ del tiempo en los brazos/ asomando viene,/ y al mundo, que en grillos/ de hielo y nieves/ tuvo el crudo invierno,/ la esperanza vuelve (...)./ El blando favonio/ que llegar la siente,/ con grato susurro/ las alas extiende» («Idilios», VI, «La primavera», vv. 1-16) ${ }^{45}$. Probablemente, se siente, por otro lado, el eco del «Solvitur acris hiems vice veris et favonii» (I, iv), aunque sin el tono grave del final de la oda horaciana. Esta construcción tuvo seguidores en los Siglos de Oro, como fray Luis de León: «Recoge $y a$ en el seno/ el campo su hermosura(...)./ Ya Febo inclina el paso...» (XI, 1-2; y 6); como Francisco de Rioja, soneto III: «Ya del sañudo Bóreas el nevoso/ soplo cessó...» (vv. 1-2) ${ }^{46}$.

Otro detalle horaciano anotaremos. Meléndez tomará los versos iniciales de un poema del venusino ( Audivere, Lyce, di mea vota, di/ audivere, Lyce: fis anus...»: IV, xiii, 1-2: 'Oyeron, Lice, los dioses mis deseos; los oyeron, Lice: te has hecho vieja') para construir el comienzo de dos poemas. Nótese que el tema del poeta latino es inverso al de Meléndez: aquél se regocija porque una mujer se ha hecho vieja y fea; el poeta dieciochesco se alegra no del mal, sino del bien. En el primer caso, la alegría se cifra en el nombramiento del amigo Eugenio de Llaguno como Ministro de Gracia y Justicia (1794): «En fin mis votos el benigno cielo/ oyó, querido

${ }^{44}$ Cf. Obras en verso, I, pp. 86-87.

${ }^{45}$ Cf. Obras en verso, I, p. 259.

${ }^{46}$ Cf. Poesía, p. 139. Véanse otros ejemplos de Rioja: «Ya la hoja que verde ornó la frente/ desta selva, don Juan, en el verano,/ tiene amarilla por el suelo cano...» (soneto IX, vv. 1-3, p. 147); «De Febo Apolo el claro ardiente rayo/ ya muda l'alta nieve en tibias ondas/ del más elado i riguroso monte;/ sólo a mi pura luz no cambia el yelo...» (sextina II, vv. 1-4, p. 152); «Fonseca, ya las oras/ del ivierno aterido,/ aunque tarde, se fueron...» (silva II, «Al verano», vv. 1-3, p. 193). 
Elpino...» (vv. 1-2) ${ }^{47}$. En el segundo caso, Oda XXVI filosófica y sagrada, Meléndez siente «Afectos y deseos de un español al volver a su patria» (1814): «Benigno en fin el cielo/ mis suspiros/ oyó...» (vv. 1-2) ${ }^{48}$. Como se ve, veinte años median entre los dos poemas; las circunstancias son muy diferentes; pero la imitatio horaciana enlaza la alegría y la esperanza en la circunstancia dramática ${ }^{49}$.

En la cuerda amorosa de Meléndez no falta el cultivo de un tópico de vieja estirpe: el paraclausithyron (en latín, exclusus amator), consistente en el lamento expresado por el enamorado ante la puerta infranqueable de la amada. ${ }^{50}$ Así, en el soneto IX, «El propósito difícil»: "iQué de veces en lágrimas bañado/ me halló el alba besando tus umbrales/ o la lóbrega noche, siempre iguales/ mi ciego anhelo y tu desdén helado!» (vv. 5-8 ${ }^{51}$. El poeta continuará, pese al desdén de la amada, siempre en su amor (v. 14). Difícil encontrar un precedente exacto en la tradición clásica. El tópico lo cultiva Horacio, tantas veces portavoz de los modos y temas de la lírica grecolatina. Quizá el poema en que ocupa una posición nuclear sea III, $x$, que ha tenido repercusión en la lírica española ${ }^{52}$ :

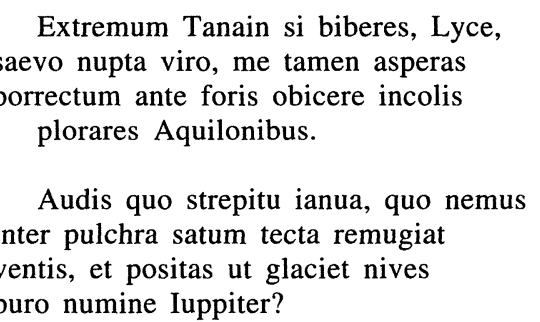

('Aunque bebieras las aguas del lejano Tanais, Lice, casada con un terrible esposo, me llorarías al verme tendido ante tu puerta, a merced de los Aquilones, huéspedes de la tierra. ¿Oyes el estrépito de la puerta, cómo el

${ }^{47}$ Cf. Obras en verso, II, p. 767.

${ }^{48}$ Cf. Obras en verso, II, p. 941.

${ }^{49}$ Son versos horacianos muy imitados por los líricos españoles: cf. Cristóbal de Mesa, Rimas, XXXV, v. 1: «Silvia, oyó el cielo, oyó mi ruego el cielo» (ed. de Senabre, p. 81).

${ }^{50}$ Cf. Henderson (1973).

${ }^{51}$ Cf. Obras en verso, I. p. 458.

${ }^{52}$ Existen ejemplos en nombres como Francisco de Rioja, Pedro Soto de Rojas, Villegas o Lope de Vega, La Arcadia, II, pp. 286-287, canto del pastor Lucindo: «¡Cuántas veces me halló en su puerta el día/ con las tempranas guindas y cerezas/ que con el verde helecho entretejía!/ Si no podía hablarla, iqué tristezas!/ Sus puertas, sus ventanas coronaba/ de madreselvas y silvestres nuezas./ Con esto, cuando Albania despertaba/ y daba por sus rejas sol al mundo,/ conocía que yo velando estaba./ ¿No has visto un perro con gemir profundo,/ si le deja su amo, herir la puerta?/ Pues yo era así, y en la lealtad segundo». Cf. Ramajo (1993). Para el tópico en Quevedo, cf. Orobitg (1996). La nómina se podría ampliar, pero no se trata aquí de presentar una enumeración exhaustiva. 
viento muge en el bosque plantado en tu hermosa mansión, cómo Júpiter hiela las nieves, con su divinidad serena?').

Pero Horacio no va a tener la paciencia que luego demostrará Valdés: «non hoc semper erit liminis aut aquae/ caelestis patiens latus» (vv. 1920: 'no siempre este costado podrá soportar tus umbrales y el agua caída del cielo').

De nuevo reelabora el tópico Meléndez en la oda XII, «La reconciliación», diálogo entre Lidia y Fileno, que recuerda otra oda horaciana (III, ix), en que conversan el propio Horacio y su antigua amada Lidia ${ }^{53}$. El diálogo transcurre con sabor eglógico, en virtud no sólo del espacio literario sino del uso de los versos amebeos: «Ingrato, cuando a hablarme/ a mi choza de noche te llegabas,/ ¡cómo para ablandarme/ al umbral te postrabas/ y en dolorido llanto lo regabas!» (vv. 1-5). Y sigue Lidia: « $i Y$ cuando tú engañoso/ me importunabas que la choza abriera,/ jurándote mi esposo? (...)» (vv. 21-23).

4. La poesía influida por la tradición clásica se pliega convenientemente a los hitos de la vida. Nada tiene de extraño, pues, que encontremos en Meléndez el cultivo del Genethlíacon, cuyo mejor exponente, por la fidelidad al paradigma clásico, es la oda $\mathrm{XX}$, «El nacimiento de Jovino». En este poema, los ángeles, como las Musas o las Gracias de la tradición clásica, al nacer Jovellanos, emitieron la profecía de una vida dichosa: «Empero hombre de bien Jovino nace;/ y a su cuna corriendo las virtudes/ en sus brazos le mecen/ y en su amable sonrisa se embebecen./ Naturaleza al verse ennoblecida/ se regocija; y mil alegres himnos/ los ángeles cantando,/ sus venideras dichas van cantando»(vv. 25-32) ${ }^{54}$.

En la oda XLIX, dedicada a don Eugenio Llaguno, en su ascensión al Supremo Consejo del Estado, aparece el esquema del genethlíacon, de manera original: el nombramiento para tan alto cargo del amigo citado conlleva una aetas aurea, como la que anunciaba el nacimiento del misterioso niño de la bucólica IV de Virgilio, de la que en este poema brotan claras influencias ${ }^{55}$ : «El siglo antiguo de Saturno torna,/ la virgen vuelve

${ }^{53}$ Cf. Obras en verso, II, pp. 638-640. Ya señaló tal influjo Cristóbal (1990: 61). El diálogo de la oda le confiere cualidades teatrales que Molière supo aprovechar en Amants magnifiques, $3 .^{\circ}$ intermedio, escena de Philinte y Climène (cf. Villeneuve 1929: 116).

${ }_{54}$ Cf. Obras en verso, II, p. 655. Para estudiar el genethlíacon clásico (Virgilio, bucólica IV; Estacio, «Genethliacon Lucani ad Pollam»; «Laus Serenae» de Claudiano...), neolatino y romance, véanse Pérez-Abadín (1995) y las notas que aportamos a la oda IV de Fray Luis en nuestra edición de las Poesías del agustino (Crítica: en prensa).

${ }_{55}$ También Leandro Fernández de Moratín sigue el mismo lugar virgiliano en sus odas «Al nacimiento de los serenísimos infantes mellizos, Carlos y Felipe» (1783), Poesías completas, pp. 505-511, y «Al nacimiento de la [actual] condesa de Chinchón» (1800), Ibíd., pp. 572-576. Y en esa misma senda hay que situar la égloga de Iglesias de la Casa titulada «Zagales de Carabias» (Poetas líricos del siglo XVIII, I, pp. 460-463). 
y la inocencia santa,/ toda virtud apresurada corre/ tras de tu huella» (vv. 37-40) ${ }^{56}$.

No falta el epitalamio. La oda XXII, «Filis rendida», con su invocación a Himeneo, recuerda la línea clásica, acaso con una influencia directa de Góngora, Soledades, 767-844: «Y las Gracias risueñas/ sobre mi Filis rosas derramaban,/ y aplaudiendo halagüeñas,/ 'Ven, Himeneo, ven', dulces clamaban» (vv. 45-48) ${ }^{57}$.

5. Pero la lira de Meléndez, como estamos viendo, es variada. A veces toma tonos muy serios, estoicos ${ }^{58}$. En «El pecho constante» (oda XLIV, fechada en 1814), debe traslucirse un fondo autobiográfico. Los avatares que habían golpeado a Meléndez lo llevan a fortalecerse con clásicas consideraciones estoicas. La obra remite al Horacio reflexivo. Anotemos los versos más significativos: «He aquí el pecho constante,/ que por más que se irriten/ en su daño los hádos/ no podrán sumergirle:/ encina en la firmeza/ de sus hondas raíces,/ y a los golpes y agravios/ cual la roca inflexible,/ sin que nada plebeyo/ menos haga sus timbres,/ ni en sus labios la queja/ sus virtudes mancille» (vv. 57-68) ${ }^{59}$. Se refiere a IV, iv, 57-60 ${ }^{60}$ : «duris ut ilex tonsa bipennibus/ nigrae feraci frondis in Algido,/ per damna, per caedes ab ipso/ ducit opes animumque ferro" ('como la resistente encina que el hacha de doble corte poda en el Álgido abundante en negro follaje, en medio de los embates, de las heridas, del mismo hierro saca fuerzas y vida'); aunque el poeta practica la contaminatio, y puede inspirarse en otros versos del venusino: «Iustum et tenacem propositi virum/ non civium ardor prava iubentium,/ non voltus instantis tyranni/ mente quatit solida neque Auster,/ dux inquieti turbidus Hadriae,/ nec fulminantis magna manus Iovis:/ si fractus inlabatur orbis,/ inpavidum ferient ruinae» (III,

${ }^{56}$ Cf. Obras en verso, II, p. 721. El texto de Virgilio del que se hace eco Meléndez es: «iam redit et Virgo, redeunt Saturnia regna» (IV, 6: 'vuelve la Virgen de nuevo y de nuevo el imperio saturnio', en traducción de Cristóbal 1996: 140, para quien con Virgen Virgilio se refiere a la Justicia: cf. ibíd., p. 144, y cf. p. 145 para alguna huella de este verso en la literatura española). La nota virgiliana se muestra, a veces, en un pequeño detalle. En la epístola VI, «El filósofo en el campo», Meléndez no encuentra mejor modo de comenzar su poema que con el recuerdo de la primera bucólica del poeta latino («Tityre, tu patulae recubans sub tegmine fagi», v. 1: 'Títiro, recostado tú a la sombra de una copuda encina'): «Bajo una erguida populosa encina,/ cuya ancha copa en torno me defiende/ de la ardiente canícula...» (vv. 1-3; Obras en verso, II, p. 783).

57 Cf. Obras en verso, II, p. 659. En la tradición clásica, encontramos, por ejemplo, epitalamios en Safo, Catulo, 61-62, Estacio (Silvae, I, 2) y Claudiano («Fescennina dicta Honorio Augusto et Mariae»). Véanse una relación de textos y características retóricas de este subgénero en Fordyce (1961: 236-237).

58 Para situar cronológicamente este aspecto de la poesía de Meléndez, cf. Real de la Riva (1948: 362) y Polt (1981: 38).

59 Cf. Obras en verso, I, p. 123

60 Polt (1981: 52-53) remite a Horacio, I, xxii («Integer vitae»). 
iii, 1-8: 'Al varón justo y tenaz en sus proyectos, ni la furia de los ciudadanos que convoca a malos designios, ni el rostro del amenazador tirano, ni el Austro, caudillo turbulento del agitado Adriático, ni la poderosa mano de Júpiter, dios del rayo, le golpean en su mente equilibrada: si el orbe cayera hecho pedazos, las ruinas le golpearían impávido') ${ }^{61}$.

${ }^{61}$ Es pasaje muy celebrado en las letras españolas: Garcilaso, elegía I, 196-201: «mas si toda la máquina del cielo,/ con espantable son y con rüido,/ hecha pedazos, se viniere al suelo,/ debe ser aterrado y oprimido del grave peso y de la gran rüina,/ primero que espantado y conmovido» (cf. Lapesa 1985: 145-146); Diego Hurtado de Mendoza, «Epístola a Boscán», vv. 94 ss. (cf. Morros 1995: 444); Fray Luis de León, «Príncipe de la paz»: «Y cuando todo a la redonda de él se arruine, él permanece más firme» (De los nombres de Cristo, p. 325); y «Monte»: «Si vertiendo agua las nubes y se abrieren los canales del cielo, y, saliendo la mar de madre, se anegaren las tierras y sobrepujaren como en el diluvio sobre los montes las aguas, en este monte (...) no las tememos...» (De los nombres, p. 154). Para otros textos, 'cf. nuestra edición de las Poesías de Fray Luis de León (Crítica: en prensa), comentario a la oda XV. Cf. también Blüher (1986: 308).

Aunque sea en nota, en este trabajo se está señalando someramente la huella de la literatura del Siglo de Oro español en Meléndez. Los escritores de tal período eran gustados en el círculo de amistades en el que se encuadraba nuestro poeta. Y así, fue Cadalso quien le descubrió la figura de Garcilaso (Palacios 1979: 10-11). No debe olvidarse que en 1765 Azara publicó las poesías del vate toledano, que gozaron de frecuentes reimpresiones (Gallego Morell 1972: 79-80). Probablemente, fue esta edición la que consultó Meléndez, aunque no figure en el catálogo que de su biblioteca privada estableció Demerson (1961: 53-56). Véase una sutil muestra de influencia garcilasiana: oda $\mathrm{XI}$, «Al capitán José Cadalso, de la dulzura de sus versos sáficos»: «Dulce Dalmiro, cuando a Filis suena/ tu delicada lira,/ el río por oírte el curso enfrena/ y el mar templa su ira» (vv. 1-4, Obras en verso, II, p. 636). Los versos recuerdan a Garcilaso, égloga III, 241-248: «Elisa soy, en cuyo nombre suena/ y se lamenta el monte cavernoso...» En el empleo del verbo sonar se transparenta un sustrato virgiliano: «...tu, Tityre, lentus in umbra/ formosam resonare doces Amaryllida silvas» (Bucólicas, I, 4-5). La influencia garcilasiana es frecuentísima: véase, simplemente, el soneto que comienza: «Cuando de mi camino atrás volviendo/ miro...»

Y por lo que se refiere al citado Fray Luis, permítasenos subrayar la admiración que Meléndez sentía por el agustino, de lo cual algo se ha adelantado en líneas anteriores: en la oda XXVII, «En una salida de la corte» - oda que recuerda la XIV, «Al apartamiento», de Fray Luis, aunque sin el tono religioso-, tras ensalzar a Virgilio, Anacreonte y Horacio, a Garcilaso y Herrera, dice: «...y tú en lauro coronado,/ ¡oh gran León!, que tu laúd hiriendo/ tierno en el bosque umbrío/ frenaste el curso al despeñado río» (vv. 21-24, Obras en verso, II, p. 675). En la oda XLVIII, "Al señor don Gaspar de Jovellanos» (vv. 14-16: Obras en verso, II, 717-718), España clama porque se reconozcan los méritos de Jovino, y comienza con un verso de fray Luis (X, 1: «A Felipe Ruiz»): «¿Cuándo será que pueda/ tu nombre esclarecido/ gloria dar a Madrid y sus doseles...?» En el soneto VI, «Las ilusiones de la ausencia» (Obras en verso, I, p. 456): «Ora pienso yo ver a mi señora», imita, según los editores, Polt y Demerson, el soneto luisiano: «Agora con la aurora se levanta». Cf. también la epístola dedicada a don Plácido Ugena, «sobre no atreverme a escribir el poema épico de Pelayo»: «Logre de un huerto el plácido recreo,/ la grata sombra de alameda umbría,/ de fresco viento el delicioso oreo,/ do el fácil giro, la corriente fría/ de un arroyuelo murmullante y puro/ vista y pecho me 
A ese primer poema horaciano citado (IV, iv) se refiere la oda IX, «A la Fortuna»: «aunque el asilo de mi hogar me robes,/ aunque me arrastres ominosa y fiera/ desde los campos de la dulce patria (...)/ nunca rendido mi inocente pecho,/ nunca menguado mi valor aguardes,/ ni que mi plectro varonil querellas/ gima cobardes./ Como afirmado en su robusto tronco/ añoso roble en elevada sierra/ inmóvil burla del alado viento/ la hórrida guerra,/ el justo, firme en su opinión, seguro/ de su conciencia, reirá a la suerte» (vv. 13-14 ${ }^{62}$ ).

También en esta lira seria Meléndez encuentra en Horacio fórmulas lingüísticas para crear el tejido verbal. Así, en el «Idilio sacro a Santo Tomás» (idilio VII, vv. 13-16), brotan en la línea horaciana («Quem virum aut heroa lyra vel acri/ tibia sumis celebrare, Clio?», I, xii, 1-2: ¿¿A qué varón, a qué héroe, Clío, pretendes celebrar con la lira o con la aguda flauta?'), en la que también se incardinaba Fray Luis de León, del cual es aquí claramente deudor, las interrogaciones con las que pretende seleccionar los elementos del canto: «¿Cuál gran virtud, cuál hijo,/ de la Iglesia triunfante,/ será bien que este día/ con tu favor yo cante?» ${ }^{63}$. En efecto, Fray Luis había comenzado así su oda XIX, «A todos los santos» ${ }^{64}$ : ¿¿Qué santo o qué gloriosa/ virtud, qué deidad que el cielo admira,/ ¡oh Musa poderosa/ en la cristiana lira!,/ diremos entretanto que retira/ el sol con presto vuelo...» (vv. 1-6) ${ }^{65}$.

La nota estoica resuena de nuevo en la oda $\mathrm{X}$, «A un amigo en las Navidades». Es el tópico horaciano del «Beatus ille», pero con la impronta de Fray Luis (oda I) y del capitán Fernández de Andrada: «Feliz el sabio humilde/ que en ocio vive, exento/ de miedo y esperanzas,/ bastándose a sí mesmo./ Un libro y un amigo,/ pacífico y honesto/ le ocupan, le en-

colmen de alegría; / y en grata soledad libre y oscuro,/ una casilla, cómoda aunque breve,/ asilo ofrezca a mi humildad seguro» (Obras en verso, II, pp. 805-806). Allí leerá, entre otros autores, al «gran León» (v. 138). De Fray Luis también se acuerda en la oda XXIV filosófica y sacra, «Consuelos de un inocente, encerrado en una estrecha prisión», en que cita a otros escritores presos: Camoens, Quevedo, Cervantes, además del citado Fray Luis (cf. vv. 129-140, Obras en verso, II, pp. 934-935). Cf. Atkinson (1933) y Arce (1981) para el estudio de la huella luisiana en la poesía dieciochesca. Todavía en las siguientes páginas se aludirá a los ecos de Fray Luis en Meléndez.

${ }^{62}$ Cf. Obras en verso, II, pp. 633-634 (los editores relacionan el poema con el horaciano «Integer vitae...»: Carmina, I, xxii).

${ }^{63}$ Cf. Obras en verso, I, p. 263. Ya anteriormente hemos presentado algunos apuntes sobre la admiración de Meléndez por Fray Luis y de la influencia que éste ejerce en su estro.

${ }^{64}$ En la numeración de la edición de Quevedo (1631), cuyas lecturas seguimos siempre en este trabajo.

${ }^{65}$ El mismo procedimiento sigue Iglesias de la Casa en su oda V, «En loor de los héroes españoles» (Cristóbal 1990: 60): «¿Cuál héroe invicto, oh sacra Melpomene,/ qué hazaña portentosa/ del ibero valor querrás piadosa/ que en mi agitada cítara resuene...?» (vv. 1-4, Poetas líricos del siglo XVIII, I, p. 468). 
tretienen/ y colman sus deseos» (vv. 49-56) ${ }^{66}$. Resuenan, en efecto, junto a versos luisianos (por ejemplo: «libre de amor, de celo,/ de odio, de esperanzas, de recelo», I, 39-40), ecos de la Epístola moral a Fabio: «Un ángulo me basta entre mis lares,/ un libro y un amigo...» (vv. 127-128) ${ }^{67}$.

La oda V, «A don Salvador de Mena en un infortunio» ${ }^{68}$, sigue de lejos a Horacio II, ix, «Non semper imbres nubibus hispidos», sin la maravillosa concisión del venusino. El primer verso nos sitúa en tal senda: «Nada por siempre dura». Y el pensamiento es coincidente en los dos poetas: la vida se afana en un eterno cambio, y no siempre el mal nos castiga: la Fortuna puede sonreír. En Meléndez, como en tantos poetas, basta el recuerdo de un modesto eco horaciano para iniciar un poema.

La amistad, pues, alcanza posición esencial en la vida y obra de Meléndez, y de ella manan poemas reflexivos que incitan a la virtud. Su poesía se nutre, en gran medida, de diálogo, como la de dos de sus poetas más queridos, Horacio y Fray Luis. En esta línea, encuentra acomodo la fórmula del propempticón, en que se augura buen viaje a la persona querida que se apresta a la partida, en el caso de Valdés, don Gaspar González de Candamo, que se dispone a cruzar el Océano, rumbo a las Américas. La huella horaciana del «Sic te diva potens Cypri» (I, iii) es evidente ${ }^{69}$, particularmente cuando el poeta se dirige suplicante a la nave: «Los ciegos vados, los escollos tristes,/ las negras nubes sobre ti apiñadas,/ y tanto monstruo que las aguas crían (...)/ mira desventurada; cauta al puerto/ torna a ganar, y deja de mi amigo/ la venturosa carga...» (vv. 18-24). Pero en esa demanda para que la nave se dirija rápida al puerto existe un eco de otro lugar horaciano, I, xiv («O navis...»): «...fortiter occupa/ portum...», vv. 2-3: 'decididamente alcanza el puerto').

En otra ocasión, Meléndez se dirige a su amigo el agustino Fray Diego González Tadeo. Nada mejor que escribir un poema que verse sobre «la verdadera paz», en liras y con recuerdos obvios de Horacio. El poeta latino y Fray Luis - los favoritos de Fray Diego- se funden en el texto: «Delio, cuantos el cielo/ importunan con súplicas, bañando/ en lloro amargo el suelo,/ van dulce paz buscando/ y a Dios la están contino demandando» (vv. 1-5) ${ }^{70}$. En efecto, anhelan la paz el labrador, el mercader, el soldado, pero ésta sólo se encuentra «en la pura/ conciencia, de esperanzas y temores/ altamente segura...» (vv. 26-28). Brota el recuerdo de Horacio,

${ }^{66}$ Cf. Obras en verso, II, p. 635.

${ }^{67}$ Cf. Epístola moral a Fabio, pp. 80-81.

${ }^{68}$ Cf. Obras en verso, II, pp. 626-627.

${ }^{69}$ Ya señalada por los editores: Obras en verso, II, p. 777. También Cadalso cultiva el propempticón en la oda «A la nave en que se embarcó Ortelio en Bilbao para Inglaterra» (Poetas líricos del siglo XVIII, t. I, p. 267: cf. Cristóbal 1990: 60). Para este tipo de poemas, cf. Ramajo (1993b: 48-51) y Schwartz (1984).

${ }^{70}$ Cf. Obras en verso, II, p. 869. 
II, xvi, «Otium divos rogat...», que pone al marino y al soldado en petición de paz, algo que no se consigue con bienes materiales: «[otium] non gemmis neque purpura ve-/ nale neque auro...» (vv. 7-8: 'el ocio, que no se compra ni con piedras preciosas, ni con púrpura, ni con oro'). También aquí la impronta de Fray Luis es merididana, en lo que toca a la famosa oda primera ${ }^{71}$. Y reaparece tal huella en el mismo poema de Meléndez, en otros versos: « Oh vida!, ¡oh sazonado/ fruto de la virtud, de la del cielo/ remedo acá empezado!,/ ¿cuándo el hombre en el suelo/ podrá seguirte con derecho vuelo!/ ¿Cuándo será que deje/ el suspirar, temer...?» (vv. 51-57) ${ }^{72}$.

6. Naturalmente, influencias hay en Meléndez de otros autores clásicos, pero no es momento para un estudio demorado ${ }^{73}$. Digamos, no obstante, la predilección que por Epicteto sentía Meléndez ${ }^{74}$. Con ello, no hacía sino seguir una tradición hispana, iniciada acaso por Sánchez de las Brozas (1600), tradición que alcanza su culminación en el siglo XVII con las dos buenas traducciones que del Enchiridión elaboran Correas (1630) y Quevedo $(1635)^{75}$.

Por otro lado, las ambiciones intelectuales de Meléndez le habían llevado a iniciar traducciones de alto aliento: pretendía trasladar al castellano la Ilíada y la Eneida ${ }^{76}$.

\footnotetext{
${ }^{71}$ Cf. Fray Luis, I, 39-40: «libre de amor, de celo/ de odio, de esperanzas, de recelo».

${ }_{72}$ Típicamente luisiana es la rima cielo-suelo. En el poema de Meléndez se perciben, en efecto, en lontananza, además de la oda primera citada, la oda II de Fray Luis: «Virtud, hija del cielo...»; y la oda X: «¿Cuándo será que pueda/ libre desta prisión volar al cielo...»

${ }^{73}$ Cf., para otra veta de la tradición clásica en Meléndez, Rodríguez de la Flor (1980).

${ }^{74}$ En carta a Jovellanos (Salamanca, 2 de agosto de 1777), Meléndez habla de la superioridad de Epicteto con respecto a Séneca: «...me gusta más Epicteto, y hallo sus reflexiones mucho más acomodadas. Cuando aprendía el griego, le [sic] traduje todo, y aun tuve después ánimo de hacerlo con más cuidado para mi uso privado, con algunas ligeras notas; pero viendo después la traducción de mi paisano Francisco Santos [se referirá a Sanctius: el Brocense], y otra del autor del Teatro universal de la vida huma$n a$, desistí de mi propósito pareciéndome que nunca pudiera yo igualar al célebre Brocense» (Poetas líricos, t. II, p. 74). No sabemos a qué traducción se refiere Meléndez al hablar del «autor del Teatro universal de la vida humana». Acaso cite de forma equivocada la traducción anónima aparecida en 1669 de Epicteto con el título de Theatro moral de toda la philosophia de los Antiguos y modernos... (cf. la descripción de Andrés 1988: 217-218).

${ }^{75}$ Según Alcina (1989: 37), existe una traducción inédita (¿al castellano?) de Alvar Gómez de Castro, anterior a 1560. Para algunas notas bibliográficas sobre la cuestión, cf. Ramajo (1992: 45, notas 18-19).

${ }^{76}$ En 1772 había comenzado una traducción de la Ilíada, que quiso continuar en 1802, sin pasar de los primeros trescientos versos, hoy perdidos, salvo los cinco primeros: cf. Rogelio Terrón de la Gándara, Homenaje a la memoria de don Juan Meléndez Valdés, Restaurador y Príncipe de la poesía castellana, p. 27. A este ensayo se refiere en carta
} 
Todo lo expuesto viene a corroborar la afirmación de que la poesía de Meléndez Valdés sólo puede comprenderse dentro de la tradición clásica. Porque nos encontramos con un poeta que en minuciosos detalles, en el léxico y en los tópicos, se está refiriendo continuamente a la antigüedad. Baste citar, todavía, como complemento y como final, para que se perciba mejor la finura de la imitatio, el uso del latinismo viola, en lugar de violeta («De la noche», vv. 5377). Con su empleo, Meléndez continúa una tradición española que se remonta, con algunos precedentes medievales, a Garcilaso («Canción de la flor de Gnido», estr. $6^{\text {a }}$, v. 3 ) $^{78}$, a Herrera ${ }^{79}$ y a Góngora ${ }^{80}$.

La poesía de Meléndez, pues, se levanta en una época en la que todavía la imitatio de la antigüedad clásica nutre la literatura. Pero se acercan tiempos en que se va a producir un desgarro hondísimo en la cultura europea. Los versos de Meléndez, pese a su sentimentalismo, quedan más allá del Romanticismo ${ }^{81}$. El sustrato clásico que conforma su obra exige que los estudiosos no cejen en el trabajo de señalar los concretos loci que el poeta meditó y reelaboró. En esa senda investigadora se inscriben las modestas páginas que el lector tiene ante sus ojos ${ }^{82}$.

a Jovellanos, Salamanca, 3 de agosto de 1776 (Cueto 1893: III, p. 40). En carta de 1778 dice al mismo amigo que no avanza en la traducción: reproduce los cinco primeros versos (Segovia, 11 de julio; cf. Cueto 1893: III, pp. 72-73; cf. Obras en verso, II, p. 1059). Sobre la traducción de la Eneida, obra trabajada entre 1802 y 1808, cf. «Noticia histórica y literaria de Meléndez», de Manuel J. Quintana, antepuesta a la edición de 1820, t. I, p. LXIII; cf. Rodríguez Moñino (1954: 13 y 19); y cf., sobre todo, Demerson (1962: 425), que edita los 293 versos del libro I conservados (véanse, además, Obras en verso, II, pp. 1075-1082).

77 «Odas anacreónticas», XLIII, Obras en verso, I, p. 122.

${ }^{78}$ Cf. Wilson (1952).

${ }^{79}$ Cf. Kossoff (1955).

${ }^{80}$ Cf. Carballo Picazo (1964: 381).

81 Vid. las puntualizaciones de Palacios (1979: 117-121) a la idea de Meléndez como un prerromántico. Pero las opiniones de los estudiosos sobre un incipiente romanticismo en la obra de nuestro poeta no son concordantes. Polt (1981: 45-47) defiende la existencia de este componente en Batilo. Con todo, habría que apurar más la investigación de las fuentes y del sentido de los poemas considerados prerrománticos por si en ellos se trasluciera un apego, todavía, de Meléndez a poetas clásicos, como un Fray Luis de León.

${ }^{82}$ Naturalmente, la visión forzosamente parcial que en estas páginas se presenta de Meléndez habrá de complementarse con una general, para la cual será preciso tener en cuento algunos de los títulos citados en las referencias bibliográficas, que, obviamente, no tienen ninguna pretensión de exhaustividad. Cf., en todo caso, como panorama resumido de la obra del poeta, el planteamiento que en su «Introducción crítica» presenta el ya citado Polt (1981: 31-56). 


\section{REFERENCIAS BIBLIOGRÁFICAS}

Alarcos García, E., «Meléndez Valdés en la Universidad de Salamanca», Boletín de la Real Academia Española, 13 (1926), pp. 49-75, 144-177 y 364-370.

AlCiNA, F. (1989): véase León, Fray Luis de.

AlONSO, D. (1967): véase Góngora, Luis de.

Alvar EZQuerra, A., «Intertextualidad en Horacio», en Horacio, el poeta y el hombre, ed. de Dulce Estefanía, Eds. Clásicas, Madrid, 1994, pp. 77-140.

Anacreónticas, ed. de M. Brioso Sánchez, Consejo Superior de Investigaciones Científicas, Madrid, 1981.

ANDRÉs, Enriqueta de, Helenistas españoles del siglo XVII, Fundación Universitaria Española, Madrid, 1988.

ARCE, J., «Fray Luis de León en Jovellanos y otros líricos del XVIII», en La poesía del siglo ilustrado, Alhambra, Madrid, 1981, pp. 123-141.

Astorgano ABAJO, A., «Meléndez Valdés y la enseñanza de las humanidades en las preceptorías de gramática (1778-1789)», Bulletin Hispanique, 1 (2001), pp. 75-125.

AtKINSON, W., «Luis de León in eighteenth-century poetry», Revue Hispanique, 81 (1933), 2è. partie, pp. 363-376.

BLÜHER, K. A., Séneca en España, vers. española de J. Conde, ed. corr. y aum., Gredos, Madrid, 1983.

BRIOSO SÁNCHEZ (1981): véanse Anacreónticas.

CARballo PICAzo, A., «El soneto Mientras por competir con tu cabello», Revista de Filología Española, 47 (1964), pp. 379-398.

Catulo, Catullus, ed. de C. J. Fordyce, at Clarendon Press, Oxford, 1961.

COLFORD, William E., Juan Meléndez Valdés. A study in the transition from Neoclassicism to Romanticism in Spanish Poetry, Nueva York, 1942.

CRISTÓBAL, V. (1990): véase Horacio.

CRISTÓBAL, V. (1996): véase Virgilio.

CUETO, Leopoldo Augusto de, Historia y crítica de la poesía castellana en el siglo XVIII, $3^{\mathrm{a}}$. ed., Rivadeneyra, Madrid, 1893, 3 vols.

DEMERSON, G., «Sobre dieciséis odas de Horacio traducidas por Meléndez Valdés», Bulletin Hispanique, 60 (1958), pp. 62-72.

-, Don Juan Meléndez Valdés et son temps (1754-1817), Klincsieck, París, 1961.

-, «Sur une oeuvre perdue de Meléndez Valdés: la traduction de l'Énéide», en Mélanges offerts à Marcel Bataillon par les hispanistes français, Burdeos, 1962.

DURÁN LÓPEZ, F., «El jesuita Vicente Alcoverro, Vargas Ponce, Moratín, Gabriel de Sancha y otros literatos dieciochescos: historia de una olvidada traducción de Horacio», Cuadernos de Ilustración y Romanticismo, 7 (1999), pp. 139-199.

FERNÁNDEZ DE ANDRADA, Andrés, Epístola moral a Fabio y otros escritos, ed. de D. Alonso, estud. prelim. de J. F. Alcina y F. Rico, Crítica, Barcelona, 1993.

FERNÁNDEZ DE MORATín, Leandro: véase Moratín, Leandro Fernández de.

FERNÁNDEZ VALLINA, E., «Horacio en Jovellanos», en Bimilenario de Horacio, ed. de Rosario Cortés y J. C. Fernández Corte, Universidad, Salamanca, 1994, pp. 377-384.

FORDYCE: véase Catulo.

GALlEGo MORELL, A. (1972): véase Garcilaso de la Vega.

GARCILASO DE LA VEGA, Garcilaso de la Vega y sus comentaristas, ed. de A. Gallego Morell, $2^{a}$. ed., Gredos, Madrid, 1972.

-, Obra poética y textos en prosa, ed. de B. Morros, Crítica, Barcelona, 1995.

GIES, David T., «Ars amicitiae, poesía y vida: el ejemplo de Cadalso», en Coloquio Internacional sobre José Cadalso, Piovan Editore, Abano Terme, 1985, pp. 151-172. Conocemos la versión de la Historia y crítica de la literatura española. 4/1. Ilus- 
tración y Neoclasicismo. Primer Suplemento, ed. de D. T. Gies y R. P. Sebold, Crítica, Barcelona, 1992, pp. 169-174.

GIL, Luis, «Una poesía juvenil desconocida de Meléndez Valdés», Prohemio, 1 (1974), pp. 65-74.

GóngORA, Luis de, Góngora y el «Polifemo», ed. de D. Alonso, 5ª ed., Gredos, Madrid, 3 vols.

-, Sonetos completos, ed. de B. Ciplijauskaité, $3^{\text {a }}$. ed., Castalia, Madrid, 1978.

GONZÁLEZ DE ESCANDÓN, Blanca, Los temas del «carpe diem» y la brevedad de la rosa en la poesía española, Universidad, Barcelona, 1938.

HENDERSON, W. J., «The Parakausithyron motif in Horace's odes», Acta Classica, 16 (1973), pp. 51-67.

HorACiO, Odes et épodes, ed. de F. Villeneuve (1929), $9^{a}$. reimpr., «Les Belles Lettres», París, 1970.

-, Odas y Epodos, ed. bilingüe de M. Fernández Galiano y V. Cristóbal, Cátedra, Madrid, 1990.

KossofF, A. D., «Una nota sobre la viola de Herrera», Revista de Filología Española, 39 (1955), pp. 350-351.

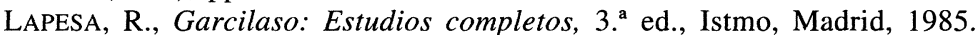

LEÓN, Fray Luis de, Poesías, ed. de J. F. Alcina, Cátedra, Madrid, 1989.

-, De los nombres de Cristo, ed. de A. Sánchez Zamarreño (Colección Austral, 190), Madrid, 1991.

LIDA DE MALKIEL, M. ${ }^{a}$ Rosa, "Transmisión y recreación de temas grecolatinos en la poesía española», Revista de Filología Hispánica, 1 (1939), pp. 30-63. Reimpr. en La tradición clásica en España, Esplugues de Llobregat, Ariel, 1975, pp. 37-99, publicación por la que citamos.

Meléndez Valdés, Juan, Poesías, Vida. e Hijos de Santander, Valladolid, 1797, 3 vols. Bibl. Universitaria de Salamanca: 11652-11654.

-, Poesías escogidas, Impr. de José Ferrer de Orga y Compañía, Valencia, 1811, 2 vols. Bibl. de Filología de la Univ. de Salamanca: 17461-17462.

- Poesías, Impr. Nacional, Madrid, 1820, 4 vols. Bibl. de la Univ. de Salamanca: 69573-69576 (todos los vols. llevan la siguiente anotación manuscrita en una de las páginas preliminares: «Regalado por la viuda del autor a la Universidad en 1821»).

- Poetas líricos del siglo XVIII, ed. de Leopoldo A. Cueto, Marqués de Valmar (18691875), reimpr. (Biblioteca de Autores Españoles, 61, 63 y 67), Madrid, 1952. Las poesías de Meléndez figuran en el t. II (BAE, 63),

-, Obras en verso, ed. de J. H. R. Polt y J. Demerson, Centro de Estudios del siglo XVIII, Oviedo, 1981-1983, 2 vols. Es la edición citada en este trabajo, aunque también se consulten otras que se anotan en el lugar correspondiente.

- Poesías inéditas, ed. de A. Rodríguez-Moñino, Real Academia Española, Madrid, 1954.

- Poesías, ed. de E. Palacios, Alhambra, Madrid, 1979.

-, Poesías selectas. La lira de marfil, ed. de J. H. R. Polt y G. Demerson (Clásicos Castalia, 108), Madrid, 1981.

MenÉndez Pelayo, M., Horacio en España (1877), 3ª. ed., Hernando, Madrid, 1926.

MeSA, Cristóbal, Las Églogas y Geórgicas de Virgilio, y Rimas, y el Pompeyo, tragedia, Juan de la Cuesta, Madrid, 1618.

- Rimas, ed. de R. Senabre (Clásicos Extremeños), Badajoz, 1991.

Montes CALA, J. G., «Del tópico grecolatino de la recusatio en la poesía de Fernando de Herrera», Criticón, 75 (1999), pp. 5-27.

Moratín, Leandro Fernández de, Poesías completas (poesías sueltas y otros poemas), ed. de J. Pérez Magallón, Sirmio, Barcelona, 1995.

Morros, B. (1995): véase Garcilaso de la Vega. 
OROBITG, Christine, «Exclusus amator: en torno a un poema de Quevedo ('A la muerte de Aminta')», en Studia Aurea. Actas del III Congreso de la AISO, GRISO-LEMSO, Pamplona-Toulouse, 1996, t. I, pp. 415-424.

PABÓN, Carmen T., «El amor en la poesía anacreóntica griega y en la de Meléndez Valdés», Cuadernos de Filología Clásica, 8 (1975), pp. 219-225.

PALACIOS, E. (1979): véase Meléndez Valdés.

PÉREZ-ABAdín BARRo, Soledad, «El Genius Natalis en la oda IV de fray Luis de León», Bulletin Hispanique, 97 (1995), pp. 493-502.

- Poetas líricos del siglo XVIII: véase Meléndez Valdés, Juan.

POLT, J. H. R., «La imitación anacreóntica en Meléndez Valdés», Hispanic Review, 47 (1979), pp. 193-206.

-, «Meléndez, traductor», en Estudios dieciochistas en homenaje al profesor José Miguel Caso González, Instituto Feijoo de Estudios del siglo XVIII, Oviedo, 1995, vol. II, pp. 263-265.

POLT, J. H. R. (1981): véase Meléndez Valdés, Juan.

POLT Y DEMERSON (1981-1983): véase Meléndez Valdés, Juan.

RACE, W. H., The classical priamel from Homer to Boethius, Brill, Leiden, 1982.

RAMajo CAÑo, A., «La Gramática General del P. Bernardo de Zamora», Studia Philologica Salmanticensia, 2 (1978), pp. 219-240.

-, «Notas sobre la recepción del Poliziano latino en España: una monodia del catedrático salmantino Blas López», Criticón, 55 (1992), pp. 41-52.

-, «Anotaciones clásicas y cristianas a un soneto de Lope ( $¿ Q$ Qué tengo yo que mi amistad procuras?')», Epos, 9 (1993), pp. 619-629.

-, «Notas horacianas para dos poemas del Brocense», Boletín de la Biblioteca de Menéndez Pelayo, 69 (1993b), pp. 45-51.

-, «El carácter proemial de la oda primera de fray Luis (y un excurso sobre la priamel en la poesía de los Siglos de Oro)», Romanische Forschungen, 106 (1994), pp. 84117.

- «La recusatio en la poesía de los Siglos de Oro», en Siglos de Oro. Actas del IV Congreso Internacional de AISO, Universidad, Alcalá, 1998, t. II, pp. 1285-1294.

REAL DE LA RIVA, C., «La escuela poética salmantina del siglo XVIII», Boletín de la Biblioteca de Menéndez Pelayo, 24 (1948), pp. 321-364.

Rioja, Francisco de, Poesía, ed. de Begoña López Bueno, Cátedra, Madrid, 1984.

RODRÍGUEZ DE LA FLOR, F., «La filiación neoplatónica de un poema de Meléndez Valdés», Dieciocho, 3 (1980), pp. 51-61.

SCHWARTZ, Lía, «Quevedo junto a Góngora: recepción de un motivo clásico», Homenaje a Ana M. ${ }^{a}$ Barrenechea, Castalia, Madrid, 1984, pp. 313-325.

TERRÓN DE LA GÁNDARA, Rogelio, Homenaje a la memoria de don Juan Meléndez Valdés, Restaurador y Príncipe de la poesía castellana. Por su sobrino, Impr. y fotograbado de Enrique Rojas, Madrid, 1900.

VeGA, Lope de, La Arcadia, ed. de E. S. Morby (Clásicos Castalia, 63), Madrid, 1975.

VILlegas, Esteban Manuel, Eróticas o amatorias, ed. de N. Alonso Cortés (Clásicos Castellanos, 21), Madrid, 1956.

VILLENEUVE (1929): véase Horacio.

VIRGILIO, Bucólicas, ed. de V. Cristóbal, Cátedra, Madrid, 1996.

WILSON, E. M., «La estrofa sexta de la Canción de la Flor de Gnido», Revista de Filología Española, 36 (1952), pp. 118-122. 


\section{RESUMEN}

Aspectos del sustrato clásico en la poesía de Meléndez Valdés, por Antonio Ramajo Caño.

En la producción poética de Meléndez Valdés, tanto en su faceta jovial como en la meditativa, brotan frecuentemente los préstamos de la tradición clásica. En el presente trabajo, se revisan bastantes de tales ecos, desde procedimientos retóricos, como la recusatio o la priamel, desde subgéneros, como el Genethlíacon, o desde tópicos, como el exclusus amator, hasta huellas minuciosas de una específica configuración lingüística, que remiten a un modelo concreto de la poesía clásica. La poesía de Meléndez, pese a su carga sentimental en ocasiones, se sitúa más allá de la gran frontera del Romanticismo.

\section{SUMMARY}

In the poetry of Meléndez Valdés, boht in its jovial and meditative facets, there frequently merge loans from the classical tratition. The present work reviews many of these echoes, ranging from rethorical devices such as the recusatio or the priamel, subgenres, such as the Genethliacon, or from commmonplaces, such as the exclusus amator, to the meticulous traces of a specific linguistic configuration, which refer to a specific model of classical poetry. The poetry of Meléndez, despite being charged with sentimentality at times, lies beyond the great frontier of Romanticism. 